\title{
THOC5, a member of the mRNA export complex, contributes to processing of a subset of wingless/ integrated (Wnt) target mRNAs and integrity of the gut epithelial barrier
}

Shashank Saran ${ }^{1 \dagger}$, Doan DH Tran ${ }^{1 \dagger}$, Sabine Klebba-Färber ${ }^{1}$, Patricia Moran-Losada², Lutz Wiehlmann², Alexandra Koch ${ }^{1}$, Himpriya Chopra ${ }^{3}$, Oliver Pabst ${ }^{3}$, Andrea Hoffmann ${ }^{4}$, Robert Klopfleisch ${ }^{5}$ and Teruko Tamura ${ }^{1 *}$

\begin{abstract}
Background: THO (Suppressors of the transcriptional defects of hpr1 delta by overexpression) complex 5 (THOC5), an mRNA export protein, is involved in the expression of only $1 \%$ of all genes. Using an interferon inducible knockout mouse system, we have previously shown that THOC5 is an essential element in the maintenance of hematopoietic stem cells and cytokine-mediated hematopoiesis in adult mice. Here we interrogate THOC5 function in cell differentiation beyond the hematopoietic system and study pathological changes caused by THOC5 deficiency.

Results: To examine whether THOC5 plays a role in general differentiation processes, we generated tamoxifen inducible THOC5 knockout mice. We show here that the depletion of THOC5 impaired not only hematopoietic differentiation, but also differentiation and self renewal of the gut epithelium. Depletion of the THOC5 gene did not cause pathological alterations in liver or kidney.

We further show that THOC5 is indispensable for processing of mRNAs induced by Wnt (wingless/integrated) signaling which play key roles in epithelial cell differentiation/proliferation. A subset of Wnt target mRNAs, SRY-box containing gene 9 (Sox9), and achaete-scute complex homolog 2 (Ascl2), but not Fibronectin 1 (Fn1), were down-regulated in THOC5 knockout intestinal cells. The down-regulated Wnt target mRNAs were able to bind to THOC5. Furthermore, pathological alterations in the gastrointestinal tract induced translocation of intestinal bacteria and caused sepsis in mice. The bacteria translocation may cause Toll-like receptor activation. We identified one of the Toll-like receptor inducible genes, prostaglandin-endoperoxidase synthase 2 (Ptgs2 or COX2) transcript as THOC5 target mRNA.
\end{abstract}

Conclusion: THOC5 is indispensable for processing of only a subset of mRNAs, but plays a key role in processing of mRNAs inducible by Wnt signals. Furthermore, THOC5 is dispensable for general mRNA export in terminally differentiated organs, indicating that multiple mRNA export pathways exist. These data imply that THOC5 may be a useful tool for studying intestinal stem cells, for modifying the differentiation processes and for cancer therapy.

Keywords: mRNA export protein THOC5, Tamoxifen inducible knockout mice, Gastrointestinal tract, Wht target mRNAs, Sepsis

\footnotetext{
* Correspondence: tamura.teruko@MH-Hannover.de

${ }^{\dagger}$ Equal contributors

${ }^{1}$ Institut fuer Biochemie, Medizinische Hochschule Hannover, OE4310

Carl-Neuberg-Str. 1, Hannover D-30623, Germany

Full list of author information is available at the end of the article
}

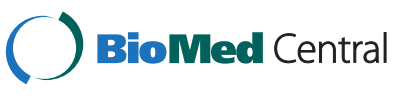

(c) 2013 Saran et al.; licensee BioMed Central Ltd. This is an Open Access article distributed under the terms of the Creative Commons Attribution License (http://creativecommons.org/licenses/by/2.0), which permits unrestricted use, distribution, and reproduction in any medium, provided the original work is properly cited. The Creative Commons Public Domain Dedication waiver (http://creativecommons.org/publicdomain/zero/1.0/) applies to the data made available in this article, unless otherwise stated. 


\section{Background}

The THO complex, which is a sub-member of TREX (transcription/export), was originally identified in Saccharomyces cerevisiae as a five protein complex (Tho2p, Hpr1p, Mft1p, Thp2p, and Tex1) [1-6] that plays a role in transcriptional elongation, nuclear RNA export and genome stability. In higher eukaryotes such as Drosophila melanogaster [7] or humans [8], three proteins, (THOC1/ hHpr1/p84, THOC2/hRlr1, and THOC3) and three additional unique proteins were identified, namely THOC5/ Fms interacting protein (FMIP) [9], THOC6 and THOC7, as members of the THO complex. However, it is still unclear whether all members of THO complex play a role as one functional unit.

We have previously shown that THOC5 is a substrate for several tyrosine kinases such as macrophage-colony stimulating factor (M-CSF, or CSF-1) receptor, Fms [9], and various leukemogenic tyrosine kinases, such as Bcr$\mathrm{Abl}$ (breakpoint cluster region-Abl tyrosine kinase fusion protein), translocation-ets-leukemia (TEL)-platelet derived growth factor (PDGF) receptor, or nucleophosmin (NPM)-anaplastic lymphoma kinase (ALK) [10,11]. In addition, we have recently shown that DNA damage causes loss of the RNA binding potential of THOC5 [12], and protein kinase $C$ phosphorylates and inhibits nuclear import of THOC5 [13], suggesting that THOC5 is regulated by extracellular signalling. Furthermore, the ectopic expression or the depletion of THOC5 in mouse myeloid progenitor or mesenchymal progenitor cell lines causes abnormal hematopoiesis or abnormal muscle differentiation, respectively, suggesting that the expression level of THOC5 is important for the normal differentiation process $[9,10,14,15]$. We have previously identified THOC5 dependent mRNAs in the fibroblast system [16]. Surprisingly, only 71 genes were downregulated by depletion of THOC5. However, over $40 \%$ of these genes were involved in differentiation processes. Furthermore, we recently examined THOC5 dependent mRNAs in monocytes/macrophages. In this system also, only 99 genes were down-regulated upon depletion of THOC5 [17]. Along the same line, depletion of THOC5 does not affect bulk poly (A) + RNA export [18] and it has been recently shown that the knockdown of THOC5 in Hela cells leads to down-regulation of 289 genes [19].

Using interferon inducible THOC5 knockout mice, we have previously shown that the depletion of the THOC5 gene causes rapid apoptosis of hematopoietic cells, but not of any other organs. After bone marrow transplantation, mice survived for more than 3 months without any symptoms, suggesting that THOC5 plays a key role in maintaining hematopoietic cells. However, since interferon is one of the important cytokines for hematopoiesis [20], the observed phenotype may be due to the synergistic effects of interferon and knockdown of
THOC5. Furthermore, depletion of the THOC5 gene resulting from treatment with poly $\mathrm{I}: \mathrm{C}$ is limited to certain organs.

We therefore generated tamoxifen inducible THOC5 knockout mice. The treatment of mice with tamoxifen caused deletion of THOC5 exons 4/5 from bone marrow, colon, stomach, jejunum, liver, and kidney. We show here that THOC5 not only plays a key role in hematopoiesis, but also in another regenerative organ, the gastrointestinal tract. On the other hand, depletion of THOC5 in terminally differentiated organs such as liver or kidney did not result in any pathological alterations, nor did it influence mRNA export. Finally, we show that a subset of wingless/ integrated (Wnt) target mRNAs is THOC5 dependent. These data suggest that mRNA export protein THOC5 controls the differentiation in a wide range of regenerative organs.

\section{Results and discussion}

THOC5 exons 4/5 were deleted from bone marrow, colon, liver, and kidney, but not from lung after tamoxifen treatment

To extend previous work on THOC5 function to a broader range of organs and cell types, we generated a novel inducible THOC5 knockout mouse strain. We used tamoxifen-induced cre-recombinase expression in Rosa26-CreER ${ }^{\mathrm{T} 2}$ mice [21]. In Rosa26-Cre $\mathrm{ER}^{\mathrm{T} 2}$ mice, the $\mathrm{CreER}{ }^{\mathrm{T} 2}$ fusion gene is under the control of the ROSA26 promoter and hence ubiquitously expressed in all organs. However, gene recombination is only induced by injection of the synthetic ligand, tamoxifen that leads to formation of an active cre-recombinase [21]. THOC5 (flox/flox) mice (Figure 1A) were mated to Rosa26$\mathrm{CreER}{ }^{\mathrm{T} 2}$ mice, generating tamoxifen inducible THOC5 knockout mice. The deletion mutation of THOC5 was induced by intraperitoneal (i.p.) injection with tamoxifen twice at 2-day intervals. We injected 5-9-week old Rosa26-CreER ${ }^{\mathrm{T} 2}(\mathrm{n}=12)$ and Rosa26-CreER ${ }^{\mathrm{T} 2}$ :THOC5 (flox/flox) mice $(\mathrm{n}=12)$ with tamoxifen. Two or four days after the first tamoxifen injection, mice were sacrificed and deletion of a functional THOC5 was analyzed by PCR using exons $4 / 5$ specific primers in genomic DNAs from bone marrow (BM), colon, kidney, liver, lung and spleen. As control, exon 20 specific PCR was performed. In all control Rosa26-CreER ${ }^{\mathrm{T} 2}$ mice and Rosa26-CreER ${ }^{\mathrm{T} 2}$ :THOC5 (flox/flox) mice without tamoxifen treatment, an exon 4/5 specific product (313 bp) and exon 20 specific product (191 bp) were detected from all organs. THOC5 exons 4/5 were deleted from bone marrow (BM), colon, kidney and liver of Rosa26$\mathrm{CreER}{ }^{\mathrm{T} 2}$ :THOC5 (flox/flox) mice within 2 days after tamoxifen treatment, but not from lung and spleen (Figure 1B). To examine whether THOC5 exons $4 / 5$ were only partially deleted in lung and spleen, genomic DNAs from lung and 


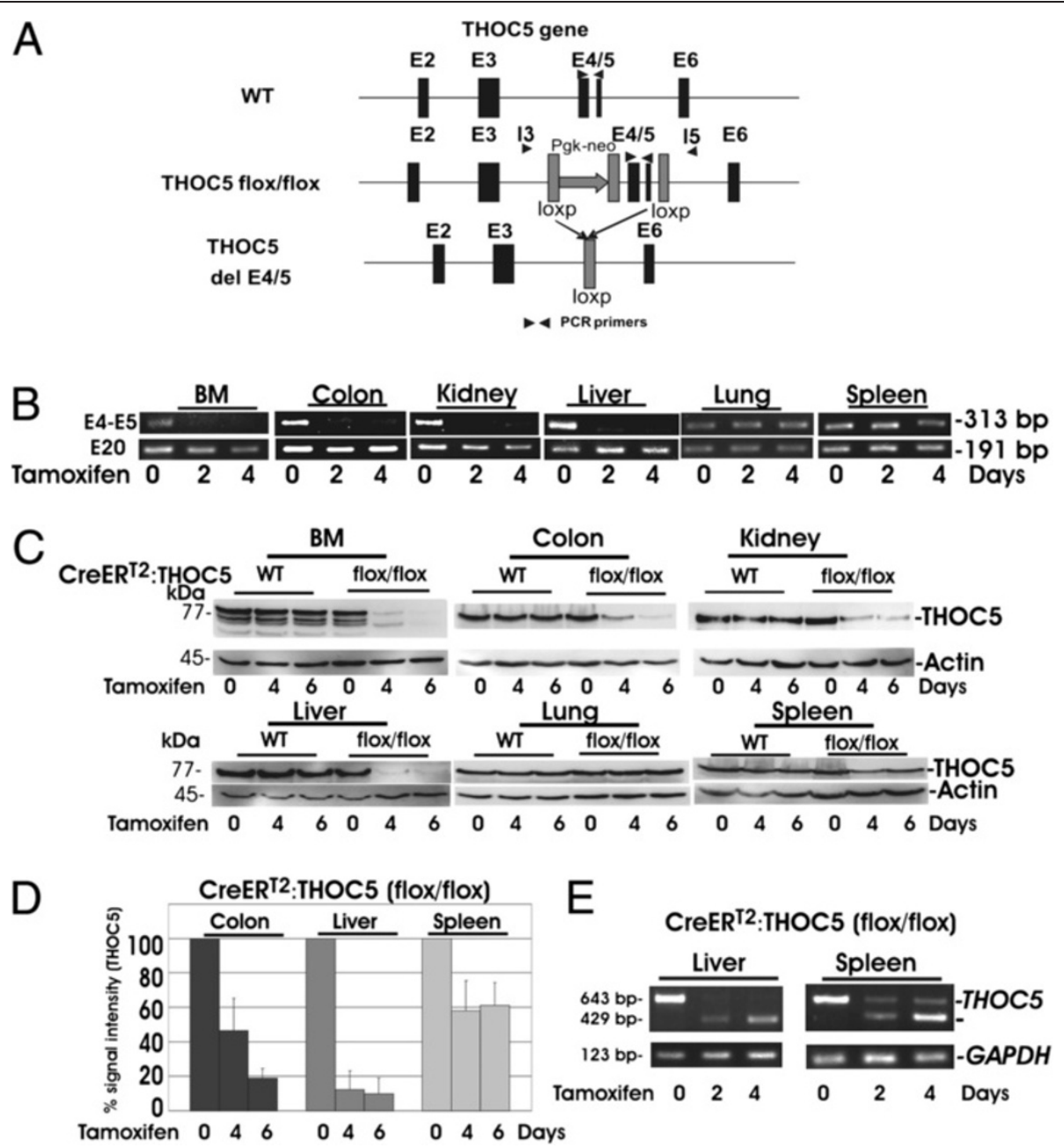

Figure 1 THOC5 exons 4/5 were deleted from BM, colon, kidney, and liver after tamoxifen treatment. (A) The genomic structure of the exon 2 (E2) to exon 6 (E6) THOC5 locus is depicted. THOC5 deficient mice were generated as described previously [23]. The loxP sites are located before E4 and after E5. Rosa26-CreER ${ }^{T 2}$ (wild type $\left.(w t)\right)(n=12)$ and Rosa26-CreER ${ }^{T 2}$ :THOC5 (flox/flox) (flox/flox) $(n=12)$ mice were injected with tamoxifen i. p. 2 times at 3-day intervals and were sacrificed 0, 2, 4 and 6 days after the first tamoxifen injection (3 mice for each preparation). Genomic DNA, protein and RNA were isolated from the same organs. (B) Genomic DNAs were supplied for the determination of deletion of exons 4/5 by PCR. PCR product: wild type allele: 313 bp; THOC5 E4/E5 del allele: 0 bp. As control, E20 specific primers (product: 191 bp) were supplied. (C) Protein was extracted from organs as indicated and subjected to THOC5 and actin specific immunoblot. Total protein amount was standardized by actin specific immunoblot. We performed 3 independent experiments and we show one example of representative data. (D) THOC5 and actin specific bands were quantified using the TINA 2.0 software (see Methods-Immunoblot Procedures). The signal intensity of THOC5 was standardized by actin band of each sample (3 mice for each preparation). The reduced percent signal intensity from mice treated with tamoxifen are shown. Mean values from three independent experiments are shown. The error bars represent standard deviation. (E) RNAs were extracted from liver or spleen of same mice as described above, and supplied for THOC5 (wt: 643 bp or delta E4/E5:429 bp) and GAPDH (123 bp) specific RT-PCR.

spleen were analyzed by PCR using introns $3 / 5$ specific primers. Corresponding bands gave 1110 bp (with exons 4/ 5) and 355 bp sizes (lacking exons 4/5), respectively. A PCR product lacking exons 4/5 (355 bp) was detected in both organs within 2 days (data not shown), indicating that THOC5 exons $4 / 5$ were only partially deleted in lung and spleen.

We next examined THOC5 at the protein level. The deletion of exons $4 / 5$ of THOC5 causes a frame shift of product and the truncated protein is expected to be only 83 amino acids long and lacking the THOC1 binding domain [22]. However, we did not detect the truncated small THOC5 product in all organs. The level of THOC5 protein did not change in organs from Rosa26-Cre $\mathrm{ER}^{\mathrm{T} 2}$ control mice before or after tamoxifen treatment, however in Rosa26-CreER ${ }^{\mathrm{T} 2}$ :THOC5 (flox/flox) bone marrow, colon, stomach, jejunum, kidney and liver the level of THOC5 was reduced to less than 20\% within 6 days in all 
mice (Figure $1 \mathrm{C}$ and D; stomach and jejunum: data not shown). The level of THOC5 product in spleen was reduced by only $40 \%$ (Figure $1 \mathrm{C}$ and D). We then examined the THOC5 mRNAs in spleen. As control, we applied mRNA obtained from liver in which the THOC5 product was reduced to $10 \%$ of control liver within 4 days after tamoxifen treatment (Figure 1E). As expected, from liver only mRNA without exons 4/5 (429 bp) was detected after tamoxifen treatment. In agreement with data obtained from genomic DNA and protein (Figure $1 \mathrm{~B}$ and $\mathrm{C}$ ), both mRNA with (643 bp) and without (429 bp) exons 4/5 were detected in spleen 2 and 4 days after tamoxifen treatment, suggesting that THOC5 is deleted in a particular population of spleen cells. Notably, in interferon inducible THOC5 knockout mice, THOC5 was depleted in bone marrow or liver, but not in the gastrointestinal tract [23], while in tamoxifen inducible knockout mice THOC5 was also depleted in the gastrointestinal tract.

\section{THOC5 inactivation results in rapid death}

To study the effects of THOC5 deletion, tamoxifen was injected twice at 2 days intervals (Figure 2, arrows) in 6week old Rosa26-CreER ${ }^{\mathrm{T2}}$ :THOC5 (flox/flox) (n=18) and Rosa26-CreER ${ }^{\mathrm{T} 2}(\mathrm{n}=10)$ control mice. All Rosa26CreER ${ }^{\mathrm{T} 2}$ :THOC5 (flox/flox) mice died within 1 week, while control mice did not show any symptoms (Figure 2). Considering the kinetics of THOC5 inactivation after tamoxifen injection and our previous observations in interferoninducible THOC5 inactivation, we speculated that loss of THOC5 in kidney, liver, bone marrow and/or gut might combine to cause lethality.

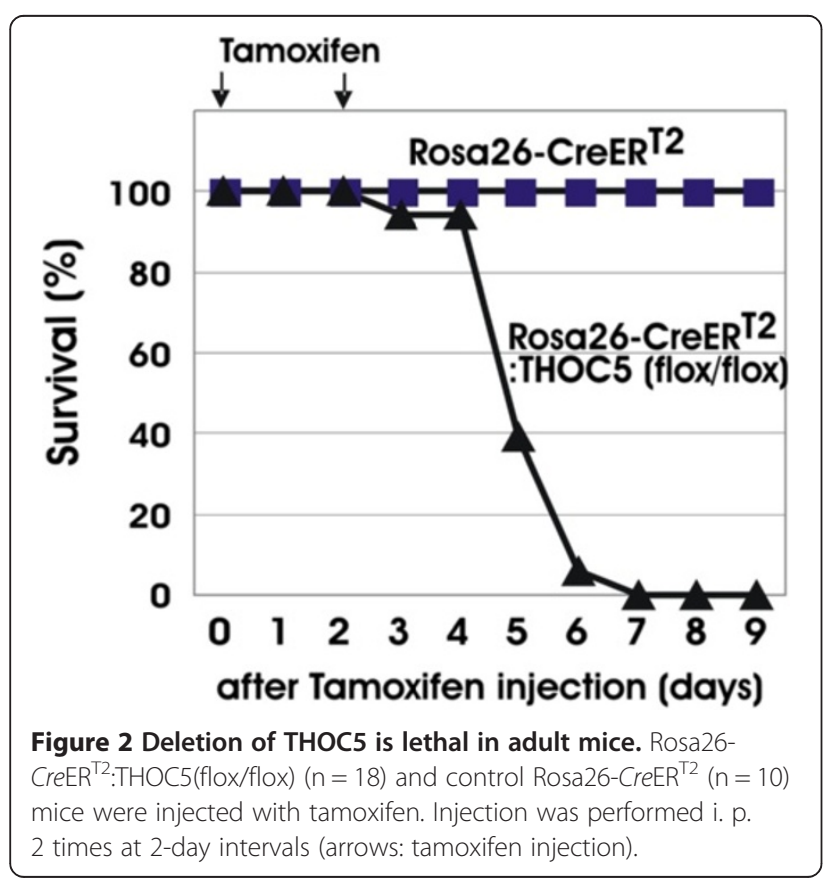

Depletion of the THOC5 gene causes loss of nucleated bone marrow cells

We have previously shown that using an interferon inducible knockout mouse system THOC5 is essential to sustain hematopoiesis in adult mice. We therefore examined whether tamoxifen inducible THOC5 knockout mice show a similar phenotype. Spleen and bone marrow were isolated from 6- to 9-week old Rosa26-CreER ${ }^{\mathrm{T} 2}: \mathrm{THOC5}$ (flox/flox) ( $\mathrm{n}=17)$ and Rosa26-CreER ${ }^{\mathrm{T} 2}$ control $(\mathrm{n}=14)$ mice on day 0 (no tamoxifen) to day 6 after tamoxifen treatment. In agreement with data using interferon inducible THOC5 knockout mice, nucleated bone marrow cells dropped in numbers already 2 days after tamoxifen treatment and after 6 days nucleated cells were very scarce (Figure 3A). Bone marrow cells from control mice did not show any alteration after tamoxifen treatment (data not shown).

\section{Loss of proliferative cells in THOC5 depleted spleen}

We then examined the effect on the spleen. Spleen weight that is normalized to total body weight of control Rosa26-Cre $\mathrm{ER}^{\mathrm{T} 2}$ mice was not altered after tamoxifen treatment, while spleen weight of Rosa26-CreER ${ }^{\mathrm{T} 2}$ : THOC5 (flox/flox) was decreased to approximately half 5 or 6 days after tamoxifen treatment (Figure 3B). It should be noted that at this period, THOC5 depleted mice also lost approximately $20 \%$ body-weight. We then counted cell numbers per mg spleen tissue. Six days after tamoxifen treatment white cell numbers were decreased to $60 \%$ in THOC5 depleted mice (Figure 3C). To determine which cell type(s) were decreased in spleen by deletion of THOC5, we next examined the morphological alterations to the spleen.

Although no obvious differences in the morphology of the splenic parenchyma were detected between THOC5 depleted and control spleens, there is a clear reduction in the number of $\mathrm{B}$ cells visualized by paired box 5 (PAX5) specific staining (Figure 3D). In addition, there is a clear reduction in the fraction of Ki67 positive proliferating cells (Figure 3D). The Ki67 positive cells in the control spleens are mainly in the area in which there is a lack of B-cells, including germinal centers, in the THOC5 depleted spleen. This suggests that THOC5 depleted spleens do not contain proliferating B-cells. On the other hand, no obvious difference was observed in CD3 positive cells before or after tamoxifen treatment (Figure 3D).

\section{Depletion of the THOC5 gene did not cause pathological} alterations in liver or kidney

We next examined other organs, kidney and liver. In agreement with our previous data [23], we did not see any pathological alterations, such as inflammation, or any activated caspase 3 positive cells in kidney or liver 

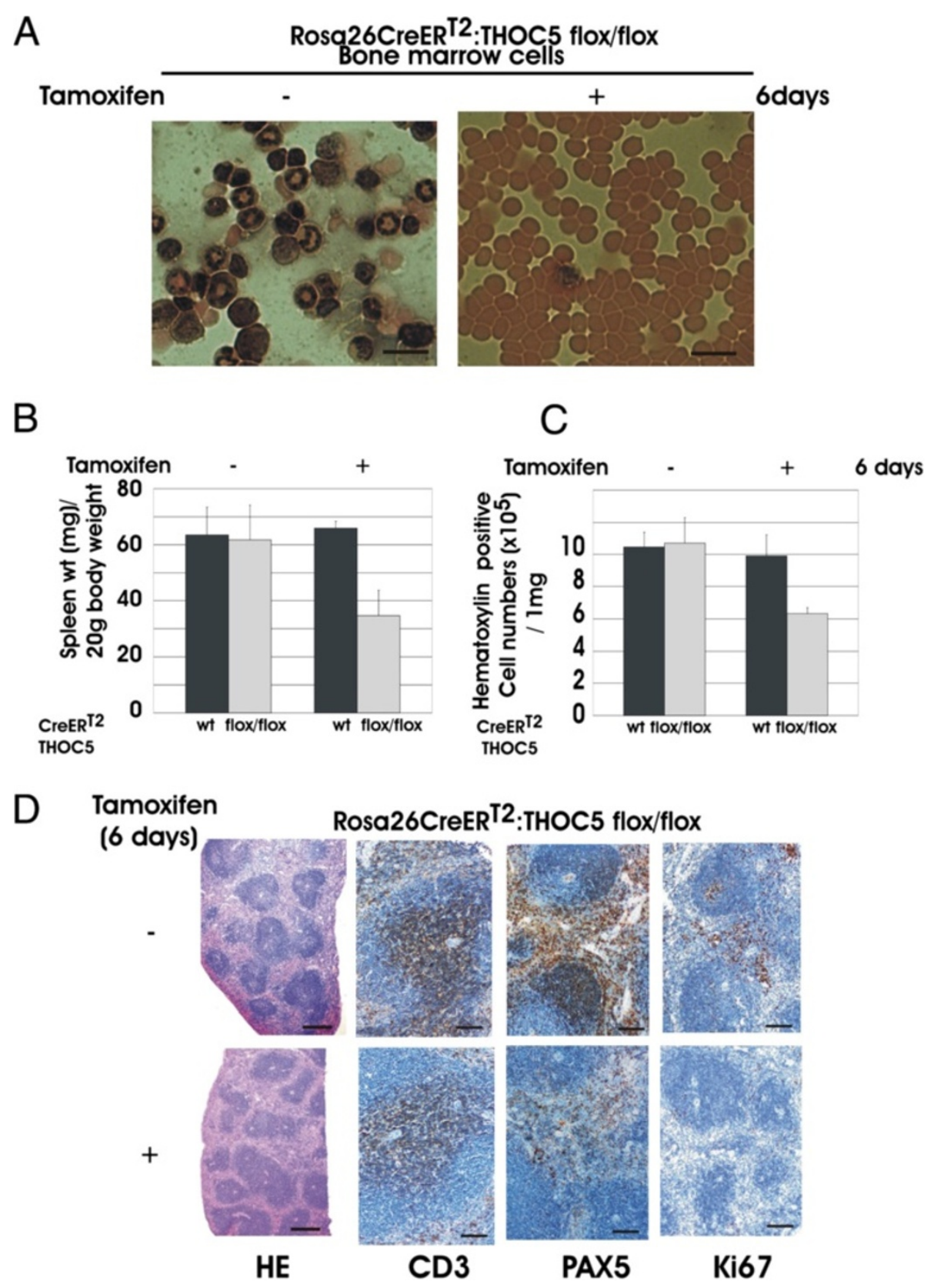

Figure 3 Depression of the THOC5 gene causes apoptosis of bone marrow cells and reduction of the B cell population in spleen. Rosa26-CreER ${ }^{T 2}$ :THOC5 (flox/flox) $(n=17)$ and control Rosa26-CreER ${ }^{T 2}(n=14)$ mice were injected with or without tamoxifen. Injection was performed i. p. 2 times at 2-day intervals. (A) Bone marrow cells were spun down onto glass slides and were then stained with May-Grünwald and Haematoxylin (May-Grünwald). We show one example of representative data. Bars represent $10 \mu \mathrm{m}$. (B, C) Spleen weight was shown as $\mathrm{mg} / 20 \mathrm{~g}$ body weight (B), haematoxylin positive cells were counted from $1 \mathrm{mg}$ spleen (C). Mean values from mice treated with tamoxifen: Rosa26-CreER ${ }^{T 2}$ :THOC5 (flox/flox) $(n=10)$ and control Rosa26-CreER ${ }^{T 2}(n=8)$ or without tamoxifen Rosa26-CreER ${ }^{T 2}: T_{H O C 5}(f l o x / f l o x)(n=7)$ and control Rosa26-CreER ${ }^{T 2}(n=6)$ are shown. The error bars represent standard deviation. (D) Rosa26-CreER ${ }^{T 2}: T_{H O C 5}$ (flox/flox) mice were treated with (+) or without (-) tamoxifen and six days after the first tamoxifen injection mouse spleens were fixed in formalin. Paraffin sections were stained by Haematoxylin and eosin (HE) or were supplied for immunohistochemical staining using CD3, PAX5 and Ki67 specific antibodies. Bars represent $800 \mu \mathrm{m}(\mathrm{HE})$ or $40 \mu \mathrm{m}$ (immunohistochemical staining).

(Figure 4A and B). Since hepatocytes produce a number of key molecules and enzymes such as albumin or transferrin for the maintenance of life, we examined whether albumin or transferrin mRNAs were exported into the cytoplasm in the THOC5 depleted liver. We isolated cytoplasmic and nuclear RNAs from $20 \mu \mathrm{g}$ of liver tissue before and after THOC5 knockdown (Figure 4C,D), and then analyzed albumin, transferrin and actin expression 


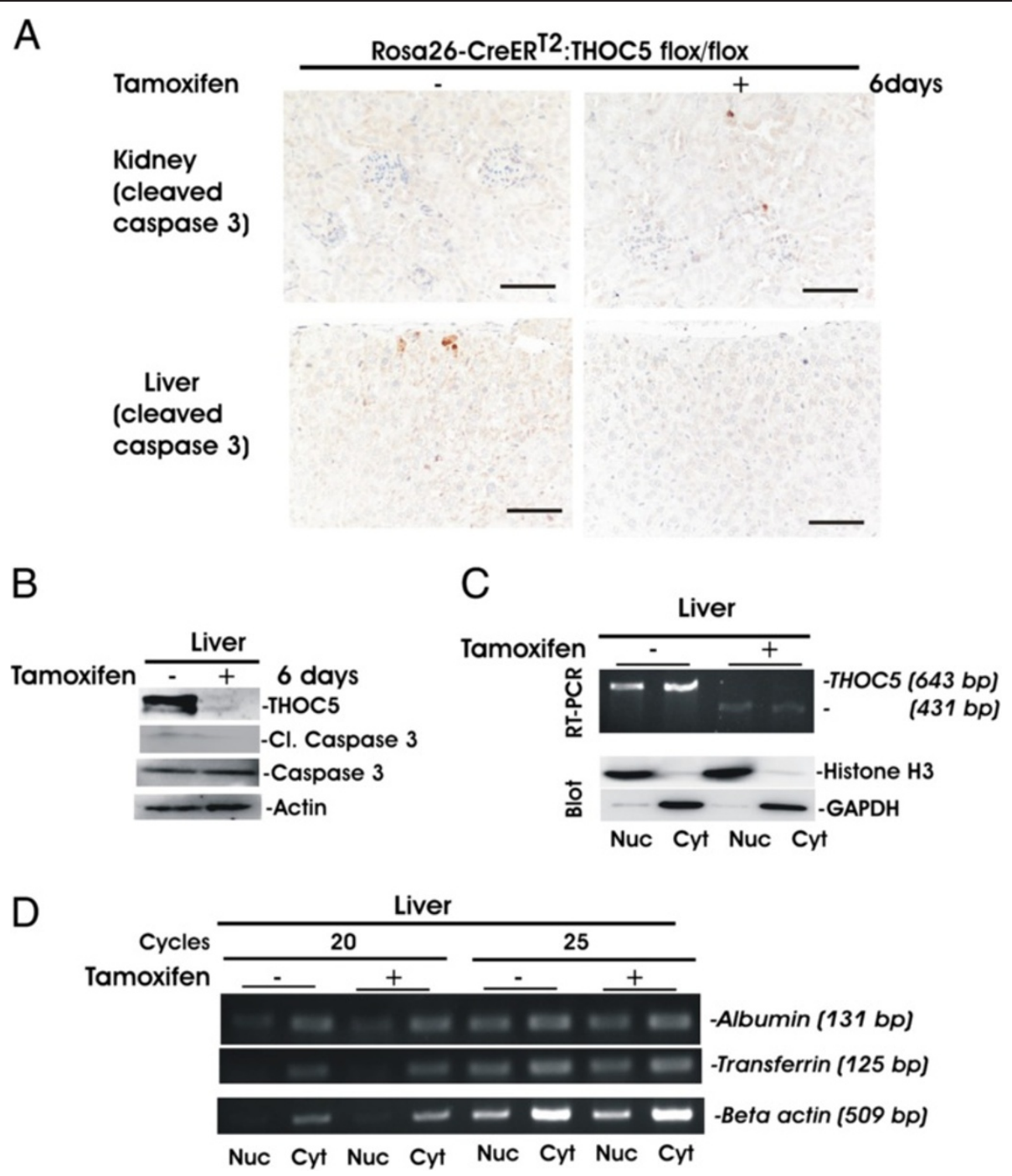

Figure 4 Depletion of the THOC5 gene did not cause pathological alteration to liver or kidney. (A) Rosa26-CreER ${ }^{\mathrm{T}}$ :THOC5 (flox/flox) mice were treated with $(+)$ or without $(-)$ tamoxifen and six days after the first tamoxifen injection, kidney and liver were fixed in formalin. Paraffin sections were supplied for immunohistochemical staining using cleaved caspase 3 antibody. Bars represent $100 \mu$ m. (B) Protein extracts from liver obtained from the same mice as in (A) were supplied for THOC5, cleaved (cl.) caspase 3, caspase 3 and actin specific immunoblot. (C) Nuclear (Nuc) or cytoplasmic (Cyt) RNA from $20 \mu \mathrm{g}$ of liver tissues before or after the tamoxifen treatment were supplied for the THOC5 specific RT-PCR or nuclear (Nuc) or cytoplasmic (Cyt) protein extracts from same tissues (200 $\mu \mathrm{g}$ of liver tissue) were supplied for GAPDH and Histone H3 specific immunoblot (Blot). (D) Aliquots of the same RNAs in (C) were supplied for Albumin, Transferrin and beta actin specific semi-quantitative RT-PCR. Cycles: Number of amplification cycles.

by semi-quantitative RT-PCR. As control for fractionation, protein extracts of both fractions obtained from $200 \mu \mathrm{g}$ liver tissues were supplied for Histone H3 (nuclear fraction), and GAPDH (cytoplasmic fraction) specific immunoblot (Figure $4 \mathrm{C}$ ). In this experiment only spliced forms of mRNA can be detected since we have chosen the primer pair for RT-PCR which is located at two different exons (Table 1). As shown in Figure 4D, upon depletion of THOC5 the export of albumin as well as transferrin mRNAs were not altered.

In addition, we examined the level of serum albumin before and after tamoxifen treatment. The level of serum albumin was not altered by depletion of THOC5 for 7 days (data not shown). Interestingly, liver expresses THOC5 at relatively high levels on the protein and mRNA levels [9], however our data revealed that THOC5 is not required for maintenance of central liver functions. This may be due to the strong regenerative potency of hepatocytes. We are currently examining the role of THOC5 in regenerating liver. Furthermore, no pathological alterations were found in other organs such as brain, heart, lung, or testicles and no clear inflammatory response was detected in THOC5 depleted organs at any time (data not shown). 
Table 1 RT-PCR primer pair sequences for selected genes

\begin{tabular}{|c|c|c|c|c|c|}
\hline Gene & Acession number & Forward primer & Reverse primer & $\begin{array}{l}\text { RT-PCR } \\
\text { (spliced) }\end{array}$ & $\begin{array}{l}\text { RT-PCR } \\
\text { (unspliced) }\end{array}$ \\
\hline Alb (exon2-exon3) & NM_009654.3 & CAAGAGTGAGATCGCCCATCG & TTACTTCCTGCACTAATTTGGCA & $x$ & \\
\hline Ascl2(exon1-exon2) & NM_008554.3 & AAGCACACCTTGACTGGTACG & AAGTGGACGTTTGCACCTTCA & $\mathbf{x}$ & \\
\hline Birc5 (exon3-exon 4) & NM_009689.2 & AGCATAGAAAGCACTCCCCTG & ССACTGTCTCCTTCTCTAAGATCC & $\mathbf{x}$ & \\
\hline Fn1 (exon41-exon43) & NM_001276408.1 & TTCAAGTGTGATCCCCATGAAG & CAGGTCTACGGCAGTTGTCA & $\mathbf{x}$ & \\
\hline GAPDH (exon2-exon3) & NM_008084.2 & AGGTCGGTGTGAACGGATTTG & TGTAGACCATGTAGTTGAGGTCA & $\mathbf{x}$ & \\
\hline GusB (exon1-exon2) & NM_010368.1 & CCGACCTCTCGAACAACCG & GCTTCCCGTTCATACCACACC & $\mathbf{x}$ & \\
\hline Mmp2 (exon1-exon2) & NM_008610.2 & CAAGTTCCCCGGCGATGTC & TTCTGGTCAAGGTCACCTGTC & $\mathbf{x}$ & \\
\hline Ptgs2 (exon8-exon9) & NM_011198.3 & TTCAACACACTCTATCACTGGC & AGAAGCGTTTGCGGTACTCAT & $\mathbf{x}$ & \\
\hline Snai1 (exon2-exon3) & NM_011427.2 & CAAGGAGTACCTCAGCCTGG & GGTCAGCAAAAGCACGGTT & $\mathbf{x}$ & \\
\hline Sox9 (exon2-exon3) & NM_011448.4 & CGGAACAGACTCACATCTCTCC & GCTTGCACGTCGGTITTGG & $x$ & \\
\hline Sox9 (exon2-intron2) & NC_000077.6 & AGTCGGTGAAGAACGGACAAG & GAATGCAAAGTCAGATACTTCTG & & $\mathbf{x}$ \\
\hline Beta-actin (exon4-exon5) & NM_007393.3 & AACACCCCAGCCATGTACGTAG & GTGTTGGCATAGAGGTCTTTACGG & $x$ & \\
\hline Beta-actin (exon4-Intron4) & AC_000027.1 & GCTGTGCTATGTTGCTCTAGACTT & TTAAGATGGAGAAAGGACTAGGC & & $\mathrm{x}$ \\
\hline THOC5 (exon1- exon7) & NM_172438.3 & TCTGCCTITTCACCTGGAAG & CTCGGTACTTTTCTGCCAGC & $\mathrm{x}$ & \\
\hline Trf (exon1-exon2) & NM_133977.2 & ACACACACACCGAGAGGAT & GGTATTCTCGTGCTCTGACAC & $x$ & \\
\hline Wnt11 (exon6-exon7) & NM_009519.2 & GGTGGTACACCGGCCTATG & TCACTGCCGTTGGAAGTCTTG & $x$ & \\
\hline
\end{tabular}

Alb (exon2-exon3): albumin (131nt); Ascl2 (exon1-exon2): Achaete scute complex homolog 2 (115nt); ; Birc5 (exon3-exon4): Baculoviral IAP repeat-containing 5 (311nt); Fn1 (exon41-exon43): fibronectin1 (154nt); GAPDH (exon2-exon3): glyceraldehyde-3 phosphate dehydrogenase (123nt); GusB (exon 1-exon2): glucouronidase beta (169nt); Mmp2 (exon1-exon2): matrix metallopeptidase 2 (171nt); Ptgs2 (exon8-exon9): prostaglandin-endoperoxidase synthase 2 (271 nt); Snai1 (exon2-exon3): snail homolog 1 (179nt); Sox9 (exon2-exon3): SRY-box containing gene 9 (163nt); Sox9 (exon2-intron2) (235nt); beta-actin (exon4exon5): (509nt); beta-actin (exon4-intron4) (191nt); THOC5 (exon1-exon7): THO complex subunit 5 homolog (643nt); Trf (exon1-exon2): transferrin (125nt); Wnt11 (exon6-exon7): wingless-related MMTV integration site 11 (183nt); (): product size.

Depletion of the THOC5 gene in gastrointestinal epithelial cells causes severe degeneration

We next examined the gastrointestinal tract. Gastrointestinal tissues were isolated from 6- to 9-week old Rosa26-CreER ${ }^{\mathrm{T} 2}$ and Rosa26-CreER ${ }^{\mathrm{T} 2}$ :THOC5 (flox/flox) mice on day 0 (no tamoxifen) to day 6 after tamoxifen treatment. Notably, 6 days after tamoxifen treatment the length of small intestine from Rosa26-CreER ${ }^{\mathrm{T} 2}$ :THOC5 (flox/flox) mice was reduced to half (from $32-33 \mathrm{~cm}$ to $17-18 \mathrm{~cm}$ ), and the length of colon was slightly reduced (by approximately 20\%). Depletion of THOC5 caused severe degenerative lesions in the small intestine (Figure 5A). The epithelial villi (Figure 5A, arrows) were disordered and shortened, and the crypts (area of the intestinal stem cells) in THOC5 depleted mice show severe dilatation and necrosis (Figure 5A, asterisk), and sometimes sloughing of cells (crypt abscesses). It should be noted that the changes are minimally associated with influx of inflammatory cells. We then examined THOC5 expression in intestinal epithelial cells. THOC5 is expressed in the nucleus of most intestinal epithelial cells, including the most prevalent enterocytes, in control mice and in non-treated Rosa26-CreER ${ }^{\mathrm{T} 2}$ :THOC5 (flox/ flox) mice, however 3 days after tamoxifen treatment, THOC5 was drastically reduced in the intestinal epithelial cells from Rosa26-CreER ${ }^{\mathrm{T} 2}$ :THOC5 (flox/flox) mice (Figure 5B). We next stained serial sections with Ki67 and cleaved caspase 3 specific antibodies. Upon depletion of THOC5, Ki67 positive cells were drastically reduced (Figure $5 \mathrm{C}$ ), while cleaved caspase 3 positive cells were detected in the crypt lesion 3 days after tamoxifen treatment, and 5 days after tamoxifen treatment cleaved caspase 3 positive cells were distributed throughout whole villi (Figure 5D), suggesting that the structural breakdown of stem cell niche, and/or bacterial infection causes apoptosis of more differentiated epithelial cells.

THOC5 expression was drastically reduced not only in small intestine, but also in caecum and colon from THOC5 depleted mice 5 days after tamoxifen treatment (Figure 5E). Furthermore, depletion of THOC5 caused severe degenerative lesions in the small intestine, and some parts of caecum, and to a lesser extent in the large intestine (Figure 5E). Severe pathological alterations in small intestinal epithelial cells may be due to the rapid turnover of epithelial cells, however we observed pathological alterations clearly in caecum and colon, where the rate of turnover and proliferation is also quite high, suggesting that THOC5 is required generally for rapidly proliferating cells in the gut. This is quite different from THOC1 (another member of the THO complex) knockout phenotype which showed that pathological alteration was observed only in stem cells from the small intestine [24]. It is not clear whether the function of THOC1 and/ or the efficiency of the tamoxifen inducible system are 


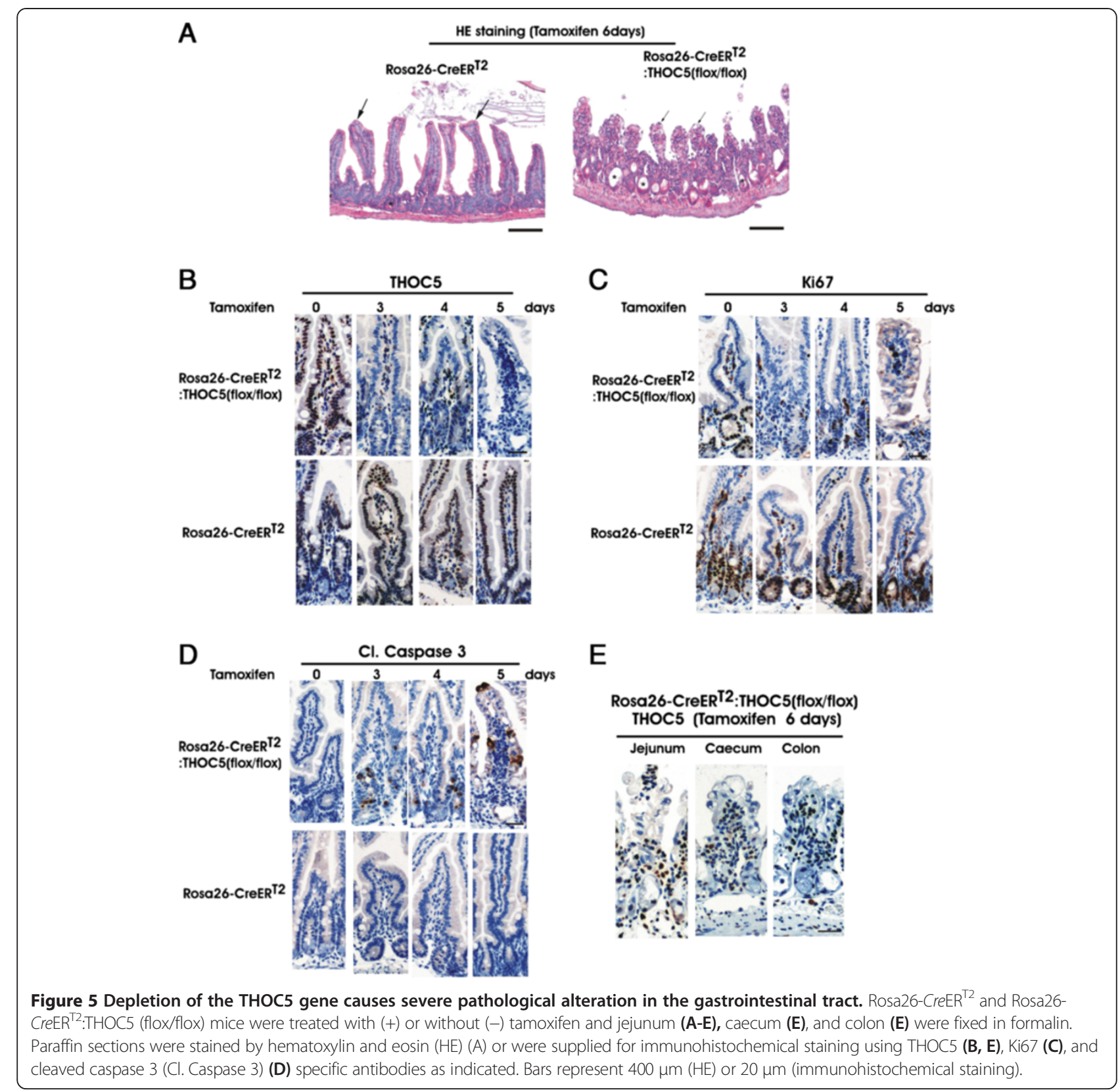

different than those of THOC5. We did not observe any pathological alterations in tamoxifen treated control mice. The damage of epithelial cells caused translocation of bacteria into the underlying blood vessels (data not shown), which may cause Toll-like receptor activation [25].

\section{Depletion of the THOC5 gene causes bacterial infection that originates from the gastrointestinal tract}

We next isolated blood from heart and incubated it on blood agar plates. No bacterial colonies grew until 2 days after tamoxifen treatment, however colonies (39 and 41 colonies/100 $\mu \mathrm{l}$ blood) were detected in blood from heart in 2 out of 3 mice 4 days after tamoxifen treatment. Five to seven days after tamoxifen treatment, more than 400 bacterial colonies were isolated from $100 \mu \mathrm{l}$ blood from heart of all THOC5 depleted mice (Table 2). Bacterial colonies were not observed from control mice at any time point. To confirm that the bacteria which were obtained from heart blood originated from the intestines, we next identified bacterial strains in blood from the heart by DNA sequencing using a SOLiD 5500XL system. Ninetyseven\% of isolated bacteria were identified as Gammaproteobacteria that include Escherichia coli that in our mouse colony represents a minor but readily detectable constituent of the gut microbiota (Table 3). This indicates that bacteria detectable in blood indeed originated from the 
Table 2 Depletion of THOC5 gene leads to sepsis

\begin{tabular}{lllll}
\hline Rosa26-CreER ${ }^{\mathrm{T} 2}:$ & \multicolumn{4}{l}{ Number of bacteria colonies } \\
THOC5 (flox/flox) & \multicolumn{1}{l}{$(100 \mu \mathrm{l}$ of blood from heart) } \\
\cline { 2 - 5 } & Day 0 & Day 2 & Day 4 & Days 5-7 \\
\hline 1 & 0 & 0 & 41 & $>500$ \\
2 & 0 & 0 & 39 & 420 \\
3 & 0 & 0 & 0 & $>500$ \\
\hline
\end{tabular}

Rosa26-CreER ${ }^{\text {T2}}$ :THOC5 (flox/flox) $(n=12)$ mice were injected with tamoxifen. Blood samples were taken from the heart on $0,2,4$, or 5-7 days after the first injection. Blood samples of $100 \mu \mathrm{l}$ were plated onto blood agar and colony numbers of bacteria from each mouse are shown.

gastrointestinal tract. These data imply that the mice died of sepsis. Since mice also exhibit several defects in immune system (Figure 3), the immune defects may also contribute to the onset of sepsis.

THOC5 is indispensable for processing of inducible mRNAs by Wnt or Toll-like receptor signaling

Wnt/beta-catenin signaling is a major regulator of homeostatic self-renewal within the intestinal crypt [26,27]. Evidences have accumulated that the THO complex plays an important role in processing of a subset of genes induced by growth factors/cytokines, serum or heat-shock. Thereby, the THO complex is recruited to its target genes and then binds to the target mRNAs [12,16,19,28,29]. We next examined whether Wnt target mRNAs are processed in a THOC5 dependent manner. It must be noted that we have previously identified THOC5 target mRNAs using the mouse embryonic fibroblast system [16]. One of these target mRNAs is SRY-box containing gene 9 (Sox9) mRNA which is one of the known Wnt targets [30-35]. We performed Sox9 specific in situ hybridization in THOC5 depleted intestines. Sox 9 transcripts were detected in the intestinal crypt in control intestines, however upon depletion of THOC5, the Sox9 transcript was reduced (Figure 6A). We further examined other Wnt target mRNAs, achaete-scute complex homolog 2 (Ascl2) [31], and fibronectin 1 (Fn1) [35]. In control intestines Ascl2 is expressed in the intestinal crypt [31], while Fn1

Table 3 Depletion of THOC5 gene causes bacterial infection that originated from the gastrointestinal tract

\begin{tabular}{ll}
\hline Bacteria & Percent \\
\hline Gammaproteobacteria & $\mathbf{9 7 . 9}$ \\
Escherichia coli & 76.7 \\
Proteus (genomic island) & 0.6 \\
Citrobacter rodentium & 0.25 \\
Enterobacter spec. & 0.1 \\
Others & 20.25
\end{tabular}

Bacteria derived from mice treated with tamoxifen for 6 days were grown overnight on blood agar and the bacterial DNA was isolated. Bacterial strains were identified by sequencing as detailed in Methods. Percent of bacterial strains from all bacteria are shown. was detected also in villi (Figure 6A). Upon depletion of THOC5, the Ascl2 but not Fn1 transcripts were reduced (Figure 6A). Beta-actin transcripts were detected at unaltered levels in control and THOC5 depleted small intestine. These data suggest that some of Wnt target mRNAs may be THOC5 dependent. However, THOC5 depletion partially causes the loss of cellularity in the small intestine, and we therefore cannot rule out that depletion of Wnt target mRNAs is simply due to the pathological alteration of the small intestine or due to a reduction in the numbers of cells expressing these mRNAs. We then further confirmed that Wnt target mRNAs are indeed THO complex dependent by isolating THOC5-mRNAs complex $[12,16]$. For this experiment, endogenous THOC5 was immunoprecipitated by THOC5 specific monoclonal antibody from the nuclear fraction from mouse embryonic fibroblasts, or mouse hepatocellular carcinoma cell line, HEPA1-6. As control, the same fraction was precipitated by normal mouse IgG. Notably, THOC1 was detected in the THOC5 specific immunoprecipitates, but not in the control IgG precipitates (Figure 6B). THOC5-mRNA complex was examined by RT-PCR using specific primers for detection of 7 Wnt target mRNAs [30-35], namely, the Sox9, Ascl2, snail family zinc finger 1 (Snai1), winglessrelated MMTV integration site 11 (Wnt11), Baculoviral IAP repeat-containing 5 (Birc5 or Survivin), matrix metallopeptidase 2 (MMP2) and $F n 1$, and as controls, GusB and beta-actin transcripts were examined. As shown in Figure 6B, Wnt target mRNA, Sox9, Ascl2, Snai1, Wnt11, and Survivin, but not MMP2 or Fn1, were detected in the THOC5-mRNAs complex, indicating that a subset of Wnt target mRNAs are indeed THOC5 dependent. Along the same line, we recently found that cytokine induced immediate-early genes, v-ets erythroblastosis virus E26 oncogene homolog 1 (Ets1) or Ets2, but not early growth response 1 (Egr1), were THOC5 dependent, indicating that not all induced genes were THOC5 dependent [17]. We then examined one of Toll-like receptor target mRNAs, prostaglandin-endoperoxide synthase 2 (Ptgs 2 or Cox2). Ptgs 2 mRNA was also isolated in the THOC5mRNA complex (Figure 6B), indicating that Toll-like receptor signalling is also impaired by depletion of THOC5. We next examined whether THOC5 plays a role in processing of Wnt target mRNAs, Sox9 or Ascl2. We isolated nuclear and cytoplasmic RNA from THOC5 depleted mouse embryonic fibroblasts (MEF) or bone marrow derived macrophages derived from Rosa26-CreER ${ }^{\mathrm{T} 2}$ : THOC5 (flox/flox) mice. Beta actin mRNA was used as an internal control for equal amounts of cDNA used for each sample (Figure 6C, actin). As control for fractionation, aliquots of protein extracts from each sample were supplied for Histone H3 (nuclear fraction), and GAPDH (cytoplasmic fraction) specific immunoblot (Blot). Spliced Sox9 and Ascl2 mRNAs were exported in the presence of 


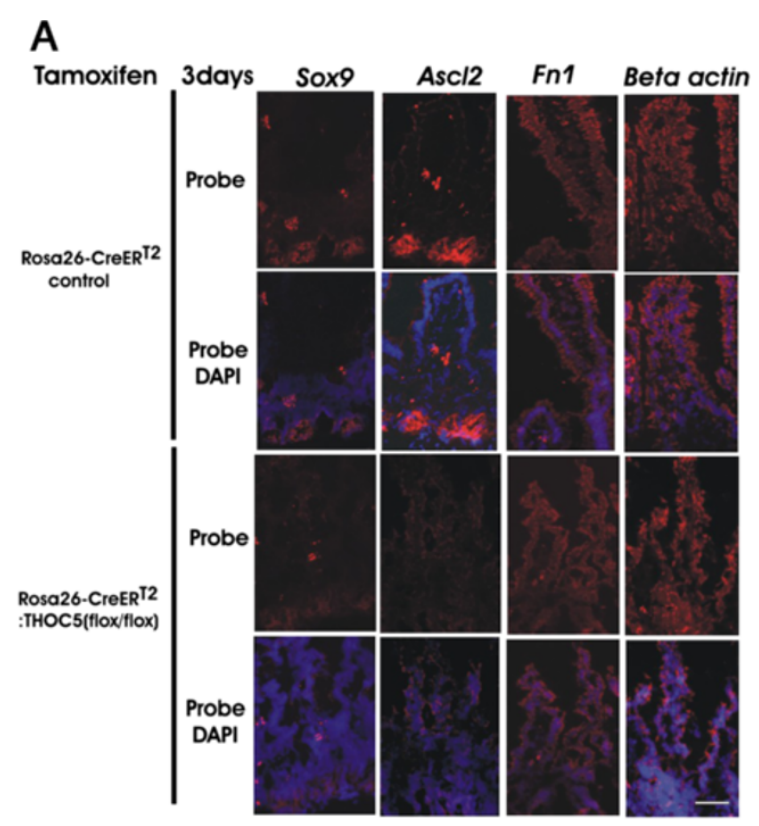

\section{B} THOC5-mRNA complex
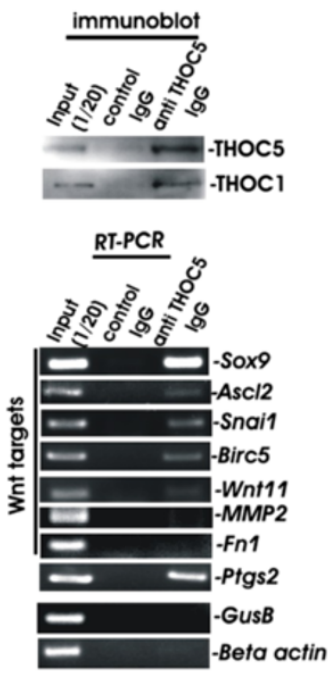

C

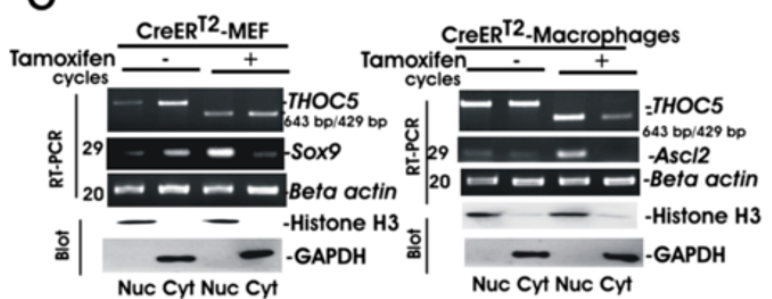

D

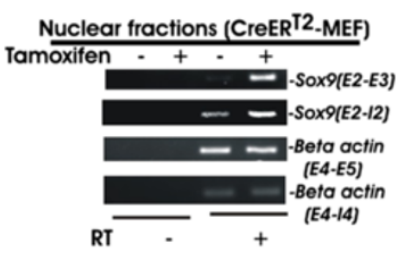

Figure 6 Wnt signaling downstream genes are THOC5 target mRNAs. (A) In situ hybridization: Frozen sections of small intestine from Rosa26-CreER ${ }^{\mathrm{T} 2}$ :THOC5 (flox/flox) or Rosa26-CreER ${ }^{\mathrm{T} 2}$ mice 3 days after tamoxifen treatment were hybridized with Sox9, Ascl2, Fn1 or beta-actin specific probes and counterstained with DAPI. Bars represent $40 \mu \mathrm{m}$. (B) Endogenous THOC5 was immunoprecipitated from the nuclear fraction of mouse embryonic fibroblasts or mouse hepatocellular carcinoma cell line HEPA1-6 using THOC5 specific monoclonal antibody (anti THOC5 $\mathrm{lgG}$ ) and control mouse lgG (control lgG). THOC5-mRNA complex was analyzed by THOC5 or THOC1 specific immunoblot or bound RNAs were examined by Sox9, Asc12, Snai1, Birc5, Wnt11, MMP2, Fn1, Ptgs2, GusB, and beta-actin specific RT-PCR. (C) MEF or Bone marrow derived macrophages were isolated from Rosa26-CreER ${ }^{\mathrm{T} 2}$ :THOC5 (flox/flox) mice. Cells were incubated with ( + ) and without $(-)$ tamoxifen $(10 \mu \mathrm{M})$ for three days, and nuclear (Nuc) and cytoplasmic (Cyt) RNAs were then isolated and applied to spliced Ascl2, Sox9, THOC5 or actin specific semi-quantitative RT-PCR using primers as described in Table 1. CDNA from all samples were standardized by adjusting equal levels of actin mRNA in both fractions. Protein extracts were supplied for GAPDH and Histone $\mathrm{H} 3$ specific immunoblot (Blot). We performed 3 independent experiments and we show one example of representative data. (D) Aliquots of nuclear RNAs in (C) were supplied for spliced (E2-E3: Exon2-Exon3) or unspliced(E2-12: Exon2-Intron2) Sox9, or spliced (E4-E5: Exon4-Exon5) and unspliced (E4-I5: Exon4-Intron4) beta actin specific RT-PCR (primers: Table 1). RT: reverse transcriptase reaction.

THOC5, however, depletion of THOC5 drastically reduced the export (Figure $6 \mathrm{C}$ ). To determine the effect of THOC5 in the target mRNA processing, we next examined the spliced and unspliced forms of Sox 9 mRNA in the nuclear fraction before and after deletion of THOC5. The unspliced form of Sox 9 mRNA also accumulated in the nucleus upon depletion of THOC5 (Figure 6D), indicating that THOC5 contributes not only to the mRNA export, but also to the efficient processing of target mRNA or the degradation of unspliced mRNAs.

Presently, it is not clear how the THO complex selects its target mRNAs. Recently, Katahira et al. [19] proposed that THOC5 controls an alternative polyadenylation site choice by recruiting cleavage and polyadenylation specific factor 6, (CPSF6, or CFIm68) on target genes. However, $70-75 \%$ of human mRNAs contain a potential alternative polyadenylation site [36]. Moreover, Snai1 (THOC5 dependent gene) does not contain this site. Alternatively, it has been previously shown in the yeast system that yeast homolog of THOC1, Hpr1 is preferentially required for transcription of either long or GC rich DNA sequences [2]. Interestingly, the coding region (not in the 3'-UTR) of Sox9, Ascl2, Snai1, and Wnt11 (THOC5 dependent genes) contain GC to a great degree (61-67\%), while THOC5 
independent genes contain 54-55\% GC. However, the target selectivity of THOC5 remains to be studied.

It has been previously shown that depletion of the Wnt target gene, Ascl2 results in a similar phenotype with pathological alterations of small intestinal epithelial cells [37] to the phenotype observed in THOC5 depleted epithelial cells, however THOC5 depleted mice showed more severe alterations of phenotype than Ascl2 -/mice. This may be due to the fact that THOC5 knockout causes depletion of the pool of Wnt target mRNAs.

These data imply that some population of genes inducible by growth factors/cytokines, Wnt signaling, and probably also Toll-like receptor signaling are THOC5 dependent, thus THOC5 plays a crucial role in proliferation/differentiation processes in regenerative organs. Furthermore, these data also provide evidence that THOC5 may be a useful tool for modification of the differentiation processes, and for cancer therapy.

\section{Conclusion}

THOC5 is indispensable for processing of only a subset of mRNAs, but plays a key role in processing of mRNAs inducible by Wnt signals. Furthermore, THOC5 is dispensable for general mRNA export in terminally differentiated organs, indicating that multiple mRNA export pathways exist. These data imply that THOC5 may be a useful tool for studying intestinal stem cells, for modifying the differentiation processes and for cancer therapy.

\section{Methods}

\section{Genotyping for Rosa26-CreER ${ }^{\mathrm{T} 2}$ :THOC5 (flox/flox) and Rosa26-CreER ${ }^{\text {T2 }}$ mice}

Generation of THOC5 (flox/flox) mice has been described previously [23]. Genotyping was performed from tail-derived sample DNA extracted with DirectPCR-Tail Lysis Reagent (Peqlab, Erlangen, Germany) by PCR using THOC5 primers flanking the floxed region with $5^{\prime}$ CCCTCGGCCCCTTTTGAG-3' and 5'-CAGCACTGG AGCGGGAGATGT-3' [23]. After crossing with Rosa26 ERT2-Cre deleter mice (A kind gift from Anton Berns, Netherlands Cancer Institute), mice were genotyped by PCR using primers Cre1 5'-CCGGGCTGCCACGAC CAA-3' and Cre2 5'-GGCGCGGCAACACCATTTT-3' for $\mathrm{Cre}$ gene and primers for floxed THOC5 gene. For the determination of exons $4 / 5$ deletion, exon $4 / 5$ specific PCR primers: 5'-CTGTGTGCACTTCATGACTCTAAAGA-3' and 5'-GAACTCCAGACATTTGGTGATCTCCT-3', introns 3/5 specific PCR primers: 5'-TGCTGGCATTG AACTGTG-3' and 5' '-CAGCACTGGAGCGGGAGAT GT-3' and exon 20 specific PCR primers: 5'-GCTATG GAGAGTGAAGTCAACGTGT-3' and 5'-CTAAAAAG CCGCAGGCACATCTT $-3^{\prime}$ ' were used.

\section{RT-PCR analysis}

RNA was isolated from mouse tissue with the High Pure RNA Isolation kit (Roche Diagnosis, Mannheim, Germany) according to the manufacturer's instructions. To isolate cytoplasmic RNAs from liver we used NEPER nuclear and cytoplasmic extraction reagents (Pierce, Thermo Scientific, Germany). Reverse transcription was carried out using oligo dT primers and the Omniscript reverse transcriptase kit (Qiagen, Hilden, Germany) following the instructions provided. Primer pairs for each PCR are shown in Table 1. PCRs were set up according to the following profile: an initial denaturation step of $94^{\circ} \mathrm{C}$ for 3 minutes, 35 cycles of $94^{\circ} \mathrm{C}$ for 30 seconds, $60^{\circ} \mathrm{C}$ for 30 seconds, and $72^{\circ} \mathrm{C}$ for 30 seconds followed by a final extension step at $72^{\circ} \mathrm{C}$ for 10 minutes. Separation of the DNA fragments was carried out on $2 \%(\mathrm{w} / \mathrm{v})$ agarose gels, stained with ethidium bromide $(2 \mu \mathrm{g} / \mathrm{ml})$ and photographed under UV light.

\section{Tamoxifen injection}

Tamoxifen (Sigma, München, Germany) was injected i.p. (1 mg/20 g body weight) into 5-9 week-old mice, two times at 2-day intervals. All animal experiments were carried out according to institutional guidelines approved by the Niedersächsisches Landesamt für Verbraucherschutz und Lebensmittelsicherheit. This study was approved under permit number: 33.14-42502-04-12/0762.

\section{Hematopoiesis assays}

Cytospin preparations were generated from bone marrow cells and contrast was enhanced by May-Grünwald and hematoxylin staining.

\section{Immunohistochemistry and immunofluorescence}

Immunohistochemical studies were performed as detailed previously [38]. Monoclonal Rat anti mouse Ki67 and polyclonal rabbit anti $\mathrm{CD} 3$ antibodies were purchased from Dakocytomation (Gloslrup, Denmark) and mouse monoclonal antibody against Pax5 was from BD Biosciences (Heidelberg, Germany). The monoclonal antibody against THOC5 was described previously [15].

\section{Immunoblot procedures}

Details of immunoblotting have been described previously [39]. Mouse organs were extracted with lysis buffer containing $10 \mathrm{mM}$ Tris $\mathrm{HCl} \mathrm{pH} \mathrm{7.6,50} \mathrm{mM} \mathrm{NaF,} 1 \mathrm{mM}$ PMSF, $10 \mathrm{mM}$ EDTA, 1\%(w/v) Triton-X 100, $8 \mathrm{M}$ Urea and protease inhibitor cocktail (Sigma, München, Germany). Monoclonal antibody against GAPDH, and polyclonal antibody against actin, were purchased from Santa Cruz Biotechnology, Inc. (Santa Cruz, CA), polyclonal antibodies against cleaved caspase 3 , caspase 3 , and Histone H3, were from Cell Signaling (Cell Signaling Technology, Beverly, MA), a monoclonal antibody against 
THOC5 was generated as described previously [15]. Corresponding proteins were visualized by incubation with peroxidase conjugated anti-mouse or anti-rabbit immunoglobulin followed by incubation with SuperSignal West FemtoMaximum Sensitivity Substrate (Pierce Protein Biology Products, Rockford, IL, USA). Results were documented on a LAS4000 imaging system (GE Healthcare Bio-Sciences, Uppsala, Sweden). Signal intensity of chemiluminescence was quantified using TINA 2.0 software (Raytest Isotopenmessgeraete $\mathrm{GmbH}$, Straubenhardt, Germany).

\section{Bacteria DNA- sequencing}

One-hundred microliter samples of blood taken from the heart were plated on blood agar and incubated overnight at $37^{\circ} \mathrm{C}$. Bacteria were isolated from the plate and genomic DNA from the bacteria was prepared. Sequencing was performed on a SOLiD 5500XL -System (Life technologies). To generate a bead-coupled fragment library for high throughput sequencing, the bacterial DNA was fragmented and processed using kits and standard protocols of Life technologies (Fragment Library Preparation: 5500 Series SOLiD ${ }^{\mathrm{Tm}}$ Systems User Guide (Part no. 4460960), $5500 \mathrm{SOLiD}^{\mathrm{Tm}}$ Fragment Library Core Kit (Part no. 4464412) and EZ Bead ${ }^{\mathrm{Tm}}$ E20 System Consumables (Part no. 4453094)). Subsequent analysis was performed with the program Genometa [40].

\section{THOC5-mRNA complex isolation}

After three times washing, mouse embryonic fibroblasts or HEPA1-6 cells were lysed with lysis buffer (10 mM Tris, $150 \mathrm{mM} \mathrm{NaCl}, 1 \mathrm{mM}$ PMSF, 0.5\% NP40, protease inhibitor cocktail, (Sigma-Aldrich, München, Germany) and RNase inhibitor), and were then frozen and thawed three times. After centrifugation, supernatants were incubated with mouse monoclonal THOC5 antibody or mouse control IgG with protein $G$ sepharose, and immunoprecipitates were then washed three times. All steps were carried out at $4^{\circ} \mathrm{C}$. Bound RNAs were employed for RT-PCR analysis [12].

\section{in situ hybridization}

Small intestines were removed from control Rosa26$\mathrm{CreER}^{\mathrm{T} 2}$ mice and Rosa26-CreER $\mathrm{ER}^{\mathrm{T} 2}$ :THOC5 (flox/flox) mice 3 days after tamoxifen injection and flushed with $3 \%$ FCS/PBS to remove faecal content. The intestines were cut open longitudinally, rolled into compact circle and frozen in Optimal cutting temperature (OCT) blocks in dry ice. Sections of 5-7 $\mu \mathrm{m}$ thickness were prepared and processed for hybridization as described below. Sections were fixed in $4 \%$ paraformaldehyde, dehydrated, digested with proteinase $\mathrm{K}$ solution (Thermo Scientific), acetylated by $0.25 \%$ acetic anhydride, washed in $2 \mathrm{X}$ saline-sodium citrate (SSC) buffer, dehydrated and hybridized with in vitro transcribed anti-sense Sox9 (NM_011448.4: Probe: 5571137 (nucleotide numbers)), Ascl2 (NM_00855 4.3 Probe: 1125-1538 (nucleotide numbers)), Fn1 (NM_001276408.1 Probe: 5021-5370 (nucleotide numbers) and beta actin (NM_007393.3: Probe 448-956 (nucleotide numbers)) RNAs overnight or 6 hours in moist chamber at $42^{\circ} \mathrm{C}$. The hybridization buffer contains $50 \%$ formamide, $0.6 \mathrm{M} \mathrm{NaCl}$, 10 mM Tris. $\mathrm{HCl}, \mathrm{pH}$ 7.5, 2 mM EDTA, 1× Denhardt's solution, $1 \mathrm{mg} / \mathrm{ml}$ yeast tRNA,10\% dextran sulphate, and $10 \mathrm{mM}$ DTT. Sections were then washed at $50^{\circ} \mathrm{C}$ in prewarmed RNA wash solution I (2X SSC, 50\% formamide, 0.1\% 2-mercaptoethanol), treated with $20 \mu \mathrm{g} / \mathrm{ml}$ Ribonuclease $\mathrm{A}$ and further washed with RNA wash solution I and II (0.1X SSC, 1\% 2-mercaptoethanol). After dehydration and drying, sections were incubated for 4 hours at RT in anti-Digoxigenin-Rhodamine (1:100, Roche Diagnostics $\mathrm{GmbH}$ ). After washing several times in Tris-buffered saline, sections were counterstained with 4',6-diamidino-2-phenylindole (DAPI). For image analysis, sections were permanently mounted in Mowiol solution.

\section{Ethics statement}

Animal experiments were performed according to the German rules and regulations (Tierschutzgesetz), and approved by the ethics committee of Lower Saxony for care and use of laboratory animals LAVES (Niedersächsisches Landesamt für Verbraucherschutz und Lebensmittelsicherheit). Mice were housed in the central animal facility of Hannover Medical School (ZTL) and were maintained as approved by the responsible Veterinary Officer of the City of Hannover. Animal welfare was supervised and approved by the Institutional Animal Welfare Officer (Tierschutzbeauftragter).

\section{Competing interests}

The authors declare that they have no competing interests.

\begin{abstract}
Authors' contributions
SS and DDHT carried out the tamoxifen injection, RT-PCR, Immunoblot, in situ hybridization, cytospin preparation, and prepared figures, SKF generated Rosa26ER ${ }^{T 2}$ : THOC5(flox/flox) mice, supervised the maintenance of mouse colony, and performed genotyping. $\mathrm{AK}$ and $\mathrm{AH}$ participated in the design of the study, supervised the study and analyses of data. HC participated cryosection and in situ hybridization and OP participated in its design and coordination, and review of the manuscript. PML and LW performed typing of bacteria strains, and RK performed the pathological analyses. $T$ participated in the design of the study, contributed to the data analysis, and wrote and finalized the manuscript. All authors participated in the discussion and approved the final manuscript
\end{abstract}

\section{Acknowledgments}

We thank Dagmar Wirth and Matthias Eder for helpful discussion, P. Chambon, and A. Berns for providing Rosa26-CreER ${ }^{T 2}$ mice, C. Bruce Boschek for critically reading the manuscript. S.K.F. was supported by the Leistungsorientierte Mittelvergabe (LOM) der MHH mit Frauen Faktor. This research was supported by DFG Ta 111/13-1. 


\section{Author details}

'Institut fuer Biochemie, Medizinische Hochschule Hannover, OE4310 Carl-Neuberg-Str. 1, Hannover D-30623, Germany. ${ }^{2}$ Pädiatrische Pneumologie, Medizinische Hochschule Hannover, OE6710 Carl-Neuberg-Str. 1, Hannover D-30623, Germany. Institut fuer Immunologie, Medizinische Hochschule Hannover, OE5240 Carl-Neuberg-Str. 1, Hannover D-30623, Germany. ${ }^{4}$ Unfallchirurgie, Medizinische Hochschule Hannover, Carl-Neuberg-Str. 1, Hannover D-30623, Germany. Institute of Veterinary Pathology, Freie Universitaet Berlin, Robert-von-Ostertag- Str. 15, Berlin D-14163, Germany.

Received: 10 September 2013 Accepted: 19 November 2013

Published: 22 November 2013

\section{References}

1. Chavez S, Aguilera A: The yeast HPR1 gene has a functional role in transcriptional elongation that uncovers a novel source of genome instability. Genes Dev 1997, 11(24):3459-3470.

2. Chavez S, Garcia-Rubio M, Prado F, Aguilera A: Hpr1 is preferentially required for transcription of either long or $\mathrm{G}+\mathrm{C}$-rich DNA sequences in Saccharomyces cerevisiae. Mol Cell Biol 2001, 21(20):7054-7064.

3. Jimeno $\mathrm{S}$, Rondon AG, Luna R, Aguilera A: The yeast THO complex and mRNA export factors link RNA metabolism with transcription and genome instability. EMBO J 2002, 21(13):3526-3535.

4. Piruat Il, Aguilera A: A novel yeast gene, THO2, is involved in RNA pol II transcription and provides new evidence for transcriptional elongationassociated recombination. EMBO J 1998, 17(16):4859-4872.

5. Strasser K, Masuda S, Mason P, Pfannstiel J, Oppizzi M, Rodriguez-Navarro S, Rondon AG, Aguilera A, Struhl K, Reed R, et al: TREX is a conserved complex coupling transcription with messenger RNA export. Nature 2002, 417(6886):304-308.

6. Reed R, Cheng H: TREX, SR proteins and export of mRNA. Curr Opin Cell Biol 2005, 17(3):269-273.

7. Rehwinkel J, Herold A, Gari K, Kocher T, Rode M, Ciccarelli FL, Wilm M, Izaurralde E: Genome-wide analysis of mRNAs regulated by the THO complex in Drosophila melanogaster. Nat Struct Mol Biol 2004 11(6):558-566

8. Masuda S, Das R, Cheng H, Hurt E, Dorman N, Reed R: Recruitment of the human TREX complex to mRNA during splicing. Gene Dev 2005, 19(13):1512-1517.

9. Tamura T, Mancini A, Joos H, Koch A, Hakim C, Dumanski J, Weidner KM, Niemann H: FMIP, a novel Fms-interacting protein, affects granulocyte/ macrophage differentiation. Oncogene 1999, 18(47):6488-6495.

10. Pierce A, Carney L, Hamza HG, Griffiths JR, Zhang L, Whetton BA, Gonzalez Sanchez MB, Tamura T, Sternberg D, Whetton AD: THOC5 spliceosome protein: a target for leukaemogenic tyrosine kinases that affects inositol lipid turnover. Brit J Haematol 2008, 141(5):641-650.

11. Griaud F, Pierce A, Gonzalez Sanchez MB, Scott M, Abraham SA, Holyoake $T L$, Tran DD, Tamura T, Whetton AD: A pathway from leukemogenic oncogenes and stem cell chemokines to RNA processing via THOC5. Leukemia 2013, 27(4):932-940.

12. Ramachandran S, Tran DD, Klebba-Faerber S, Kardinal C, Whetton AD, Tamura T: An ataxia-telangiectasia-mutated (ATM) kinase mediated response to DNA damage down-regulates the mRNA-binding potential of THOC5. RNA 2011, 17(11):1957-1966.

13. Mancini A, Koch A, Whetton AD, Tamura T: The M-CSF receptor substrate and interacting protein FMIP is governed in its subcellular localization by protein kinase $\mathrm{C}$-mediated phosphorylation, and thereby potentiates M-CSF-mediated differentiation. Oncogene 2004, 23(39):6581-6589.

14. Carney L, Pierce A, Rijnen M, Gonzalez Sanchez MB, Hamzah HG, Zhang L, Tamura T, Whetton AD: THOC5 couples M-CSF receptor signaling to transcription factor expression. Cell Signal 2009, 21(2):309-316.

15. Mancini A, El Bounkari O, Norrenbrock AF, Scherr M, Schaefer D, Eder M, Banham AH, Pulford K, Lyne L, Whetton AD, et al: FMIP controls the adipocyte lineage commitment of $\mathrm{C} 2 \mathrm{C} 12$ cells by downmodulation of C/EBP alpha. Oncogene 2007, 26(7):1020-1027.

16. Guria A, Tran DD, Ramachandran S, Koch A, El Bounkari O, Dutta P, Hauser $H$, Tamura T: Identification of mRNAs that are spliced but not exported to the cytoplasm in the absence of THOC5 in mouse embryo fibroblasts. RNA 2011, 17:1048-1056.

17. Tran DD, Saran S, Dittrich-Breiholz O, Williamson AJ, Klebba-Farber S, Koch A, Kracht M, Whetton AD, Tamura T: Transcriptional regulation of immediate-early gene response by THOC5, a member of mRNA export complex, contributes to the M-CSF-induced macrophage differentiation. Cell Death Dis 2013, 4:e879.

18. Katahira J, Inoue H, Hurt E, Yoneda Y: Adaptor Aly and co-adaptor Thoc5 function in the Tap-p15-mediated nuclear export of HSP70 mRNA. EMBO J 2009, 28(5):556-567.

19. Katahira J, Okuzaki D, Inoue H, Yoneda Y, Maehara K, Ohkawa Y: Human TREX component Thoc5 affects alternative polyadenylation site choice by recruiting mammalian cleavage factor I. Nucleic Acid Res 2013, 41(14):7060-7072.

20. Essers MA, Offner S, Blanco-Bose WE, Waibler Z, Kalinke U, Duchosal MA, Trumpp A: IFNalpha activates dormant haematopoietic stem cells in vivo. Nature 2009, 458(7240):904-908.

21. Vooijs $\mathrm{M}$, Jonkers J, Berns A: A highly efficient ligand-regulated Cre recombinase mouse line shows that LoxP recombination is position dependent. EMBO Rep 2001, 2(4):292-297.

22. El Bounkari O, Guria A, Klebba-Faerber S, Claussen M, Pieler T, Griffiths JR, Whetton AD, Koch A, Tamura T: Nuclear localization of the pre-mRNA associating protein $\mathrm{THOC7}$ depends upon its direct interaction with Fms tyrosine kinase interacting protein (FMIP). FEBS Lett 2009, 583(1):13-18

23. Mancini A, Niemann-Seyde SC, Pankow R, El Bounkari O, Klebba-Farber S, Koch A, Jaworska E, Spooncer E, Gruber AD, Whetton AD, et al: THOC5/ FMIP, an mRNA export TREX complex protein, is essential for hematopoietic primitive cell survival in vivo. BMC Biol 2010, 8:1.

24. Pitzonka L, Wang X, Ullas S, Wolff DW, Wang Y, Goodrich DW: The THO ribonucleoprotein complex is required for stem cell homeostasis in the adult mouse small intestine. Mol Cell Biol 2013, 33(17):3505-3514.

25. Abreu MT: Toll-like receptor signalling in the intestinal epithelium: how bacterial recognition shapes intestinal function. Nat Rev Immunol 2010, 10(2):131-144

26. Pinto $D$, Gregorieff A, Begthel $H$, Clevers $H$ : Canonical Wnt signals are essential for homeostasis of the intestinal epithelium. Gene Dev 2003, 17(14):1709-1713.

27. Grigoryan $T$, Wend $P$, Klaus $A$, Birchmeier W: Deciphering the function of canonical Wnt signals in development and disease: conditional loss- and gain-of-function mutations of beta-catenin in mice. Gene Dev 2008, 22(17):2308-2341.

28. Kopytova DV, Orlova AV, Krasnov AN, Gurskiy DY, Nikolenko JV, Nabirochkina EN, Shidlovskii W, Georgieva SG: Multifunctional factor ENY2 is associated with the THO complex and promotes its recruitment onto nascent mRNA. Gene Dev 2010, 24(1):86-96.

29. Pena A, Gewartowski K, Mroczek S, Cuellar J, Szykowska A, Prokop A, Czarnocki-Cieciura M, Piwowarski J, Tous C, Aguilera A, et al: Architecture and nucleic acids recognition mechanism of the THO complex, an mRNP assembly factor. EMBO J 2012, 31(6):1605-1616.

30. Blache P, van de Wetering M, DuluC I, Domon C, Berta P, Freund JN, Clevers H, Jay P: SOX9 is an intestine crypt transcription factor, is regulated by the Wnt pathway, and represses the CDX2 and MUC2 genes. J Cell Biol 2004, 166(1):37-47.

31. Fevr T, Robine S, Louvard D, Huelsken J: Wnt/beta-catenin is essential for intestinal homeostasis and maintenance of intestinal stem cells. Mol Cell Biol 2007, 27(21):7551-7559.

32. Horvay K, Casagranda F, Gany A, Hime GR, Abud HE: Wnt signaling regulates Snai1 expression and cellular localization in the mouse intestinal epithelial stem cell niche. Stem Cells Dev 2011, 20(4):737-745.

33. Lickert H, Kispert A, Kutsch S, Kemler R: Expression patterns of Wnt genes in mouse gut development. Mech Dev 2001, 105(1-2):181-184.

34. Planutiene M, Planutis K, Holcombe RF: Lymphoid enhancer-binding factor 1, a representative of vertebrate-specific Lef1/Tcf1 sub-family, is a Wnt-beta-catenin pathway target gene in human endothelial cells which regulates matrix metalloproteinase- 2 expression and promotes endothelial cell invasion. Vasc Cell 2011, 3:28.

35. von Toerne C, Schmidt C, Adams J, Kiss E, Bedke J, Porubsky S, Gretz N, Lindenmeyer MT, Cohen CD, Grone HJ, et al: Wnt pathway regulation in chronic renal allograft damage. Am J Transplant 2009, 9(10):2223-2239.

36. Elkon $R$, Ugalde AP, Agami R: Alternative cleavage and polyadenylation: extent, regulation and function. Nat Rev Genet 2013, 14(7):496-506.

37. van der Flier LG, van Gijn ME, Hatzis P, Kujala P. Haegebarth A, Stange DE, Begthel $H$, van den Born M, Guryev V, Oving I, et al: Transcription factor achaete scute-like 2 controls intestinal stem cell fate. Cell 2009, 136(5):903-912. 
38. Klopfleisch R, von Deetzen M, Weiss AT, Weigner J, Weigner F, Plendl J, Gruber AD: Weigners Fixative-An Alternative to Formalin Fixation for Histology With Improved Preservation of Nucleic Acids. Vet Pathol 2013, 50(1):191-199.

39. Koch A, Scherr M, Breyer B, Mancini A, Kardinal C, Battmer K, Eder M, Tamura T: Inhibition of Abl tyrosine kinase enhances nerve growth factor-mediated signaling in Bcr-Abl transformed cells via the alteration of signaling complex and the receptor turnover. Oncogene 2008, 27(34):4678-4689.

40. Davenport CF, Neugebauer J, Beckmann N, Friedrich B, Kameri B, Kokott S, Paetow M, Siekmann B, Wieding-Drewes M, Wienhofer M, et al: Genometaa fast and accurate classifier for short metagenomic shotgun reads. PloS one 2012, 7(8):e41224.

\section{doi:10.1186/1471-2121-14-51}

Cite this article as: Saran et al:: THOC5, a member of the mRNA export complex, contributes to processing of a subset of wingless/integrated (Wnt) target mRNAs and integrity of the gut epithelial barrier. BMC Cell Biology 2013 14:51.

\section{Submit your next manuscript to BioMed Central and take full advantage of:}

- Convenient online submission

- Thorough peer review

- No space constraints or color figure charges

- Immediate publication on acceptance

- Inclusion in PubMed, CAS, Scopus and Google Scholar

- Research which is freely available for redistribution 